\title{
Experimental Research on Vegetation Response to Artificial Warming on a Mid-Latitude High Mountain, Central Japan
}

\author{
OHMORI Hiroo,* IGUCHI Jack Hiroki,** OHTA Tsuyoshi,* \\ TERAZONO Atsuko,* and HIKITA Kengo* \\ * Department of Natural Environmental Studies, The University of Tokyo, \\ Bunkyo, Tokyo 113-0033, Japan \\ ** Graduate School of Environmental Sciences, Aomori University, \\ Aomori 030-0943, Japan.
}

\begin{abstract}
In order to investigate the vegetation response to global warming, experimental research was carried out on a high mountain of Japan for three years from 1997 to 1999. The experimental site was in the alpine zone at $2,780 \mathrm{~m}$ above sea level, near the peak of Mt. Norikura $(3,026 \mathrm{~m})$ in central Japan. Vegetation growing period is about 4 months without snow cover from early June to early October. Five open top chambers with a diameter of $80 \mathrm{~cm}$ and a height of $30 \mathrm{~cm}$ were used for temperature enhancement, and another five places were selected as controls outside the chambers. The main objectives were to clarify the differences in vegetation growth, phenology, biomass and coverage of plant between temperature-enhanced chambers and controls. To prove temperature enhancement, air temperature at vegetation height of $5 \mathrm{~cm}$ high above ground and ground temperature at root layer of $3 \mathrm{~cm}$ depth were recorded every hour in each chamber and at each control. Vegetation growth and phenology of several alpine species were measured at about four-week intervals, and biomass and coverage were measured on the last experimental day every year. The mean air temperature at vegetation height and mean ground temperature at root layer in chambers were about $0.65^{\circ} \mathrm{C}$ and $0.25^{\circ} \mathrm{C}$ higher than in the controls, respectively. Vegetation growth was significantly accelerated, and phenology was surely affected by the extension of growth period due to temperature enhancement for most of the plants observed. Vegetation growth and phenology, however, varied with species, indicating that species vary in response to warming. Differences in biomass between chambers and controls were not significant for all years, suggesting that the total growth of plants in the unit area is controlled by nutrient conditions of the soil. Through three years of experiment, coverage of Loiseleuria procumbens (Ericaceae) recognizably increased, overcoming other species in chambers, while there were no conspicuous changes in controls. It suggests that $L$. procumbens whose canopy expands horizontally over the other forbs might be more physiologically active than others under warming conditions, although vegetation growth showed positive response to temperature enhancement for most species.
\end{abstract}

Key words: vegetation response to warming, vegetation growth, phenology, biomass, plant coverage, mid-latitude high mountain, Mt. Norikura in Japan

\section{Introduction}

Climatic changes through geological time have been estimated mainly on the basis of vegetation changes reconstructed by pollen analytical research for the world (e.g. Wright et al. 1993) as well as for Japan (e.g. Tsukada 1967, 1983; Ohmori and Yanagimachi 1998). In these researches, changes in vegetation zones have been investigated in order to estimate tempera- ture changes. However, the processes of vegetation changes; how a plant species exchanged with other species through climatic change and what characteristics of plant are effectual for overcoming competition with other plants, are still obscure. On the other hand, among environmental issues, vegetation change due to global warming has become one of the most important problems because of its strong affect on agriculture, including livestock raising, forestry and even on our life style. Under these 
circumstances, in order to investigate the effect of human-enhanced greenhouse warming on vegetation at high latitudes, the International Tundra Experiment (ITEX) was established in 1990. The ITEX project has promoted research mainly on phenology and reproduction (Henry and Molau 1997). However, the processes of changes in vegetation living in a competitive world have scarcely been discussed. In order to understand deeply the vegetation changes with climatic change in geological time and for prediction of the vegetation changes due to global warming, studies on processes of vegetation change are necessary. In particular, changes in composition of plant community due to climate warming should be investigated.

The mid-latitude high mountain areas are sensitive to climatic changes because of the changeable positions of the Polar Fronts migrating over the mid-latitude. They have also severe environments for vegetation growth because of the unfavorable climatic conditions of cold, snowy and windy weather and of the poor soil conditions of thin, gravelly, less nutrient earth. Thus, the plant communities in these areas should be extremely competitive associations. Therefore, alpine plants in mid-latitude are expected to show visible changes with climate warming. Moreover, the height of alpine plants is relatively low and a unit of plant community occupies a small area. This indicates that it is easier to measure their growing rates and other properties of individual plant without disturbance of plant composition and soil structure in an actual field.

An alpine plant community is a kind of full community consisting of woody and herbaceous plants. It shows a competitive society of plants similar to other vegetation zones. Thus, the field experiment for warming effect on a full plant community at a mid-latitude high mountain area is expected to give valuable information about the vegetation changes due to climate warming of other vegetation zones. In mid-latitude alpine zones such as high mountains in Japan, some experiments for the climate warming-vegetation response have been conducted in association with the ITEX project. Very small numbers of research papers, however, are available (Nakashinden et al. 1997;
Suzuki and Kudo 1997; Fukuyo et al. 1998; Iguchi et al. 1998; Wada 1998), focused mainly on phenology. Consequently, a wide range of experimental research on vegetation changes not only in phenology but also in most aspects of plant ecology has been conducted under artificial warming at a mid-latitude high mountain in Japan for 3 years.

In order to understand ecological changes due to warming, the vegetation growth, phenology, biomass and plant coverage were chosen in our research, because they show directly the plants' traits under artificial warming. The objectives of this research were as follows:

- To gauge vegetation growth in the open top chambers (OTCs), which were used for temperature enhancement, and the controls (CTRLs), and assess the degree of the impact of warming on plants in terms of vegetation growth.

- To observe phenological changes of plants in OTCs and CTRLs, and assess how the warming affects the phenology.

- To measure biomass in OTCs and CTRLs, and analyze the differences in biomass between OTCs and CTRLs.

- To observe coverage changes of individual plant species under warming, and predict the future trend of plant community change in terms of coverage.

\section{Methods and Materials}

\section{Site information}

The experiment has been conducted near the top of Mt. Norikura, 3,026 m a.s.l., located in the southern end of the Northern Japan Alps of central Japan $\left(36^{\circ} 6^{\prime} \mathrm{N}, 137^{\circ} 34^{\prime} \mathrm{E}\right.$; Figure 1$)$. Mt. Norikura is a Quaternary volcano, but inactive during the Holocene. Its summit areas are covered with volcanic rocks, lava beds and volcanic breccias, and with some crater lakes and volcanic cones (Nakano et al. 1995). The altitudinal zone from $2,400 \mathrm{~m}$ to $2,800 \mathrm{~m}$ a.s.l. is covered with Pinus pumila scrub. It is one of the greatest Pinus pumila zones in Japan. The areas higher than $2,800 \mathrm{~m}$ are not covered with vegetation but occupied by rocky bare lands.

The experimental site was chosen on the rela- 

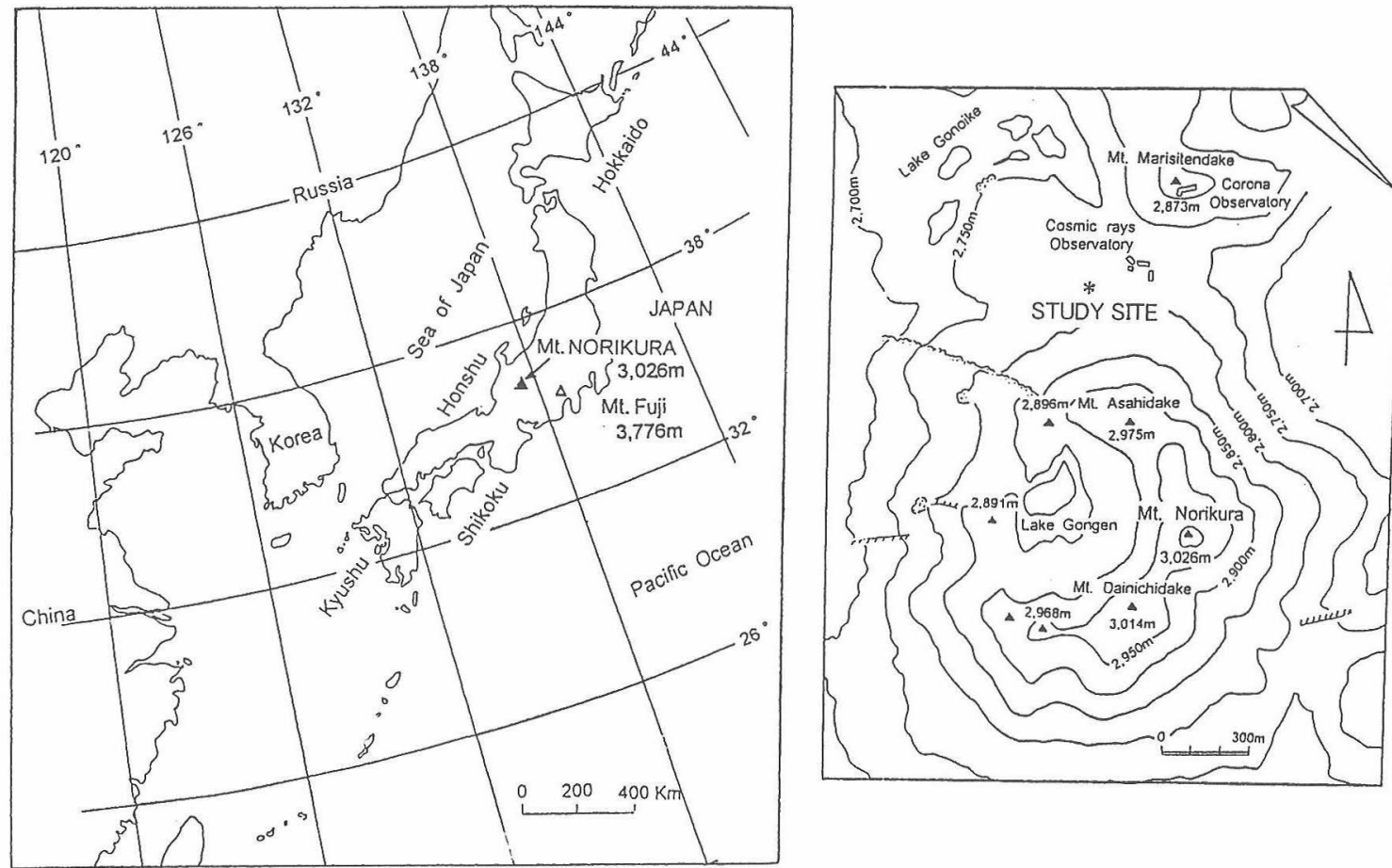

Figure 1. Map of the experimental site.

tively flat area (2,780 $\mathrm{m}$ a.s.1.) at the foot of one of volcanic cones (Figure 1). It is in a pocket of Pinus pumila scrub (about $2 \mathrm{~m}$ tall) where shrub and herb species called "Association of Vaccinium-Pinus pumila"(Gifu Prefecture 1969) are distributed in patches over the gravelly surface (Photo 1). Monthly mean temperature at $1.5 \mathrm{~m}$ height is $10^{\circ} \mathrm{C}$ in August and $-15^{\circ} \mathrm{C}$ in January and February, and annual mean temperature is $-3^{\circ} \mathrm{C}$. The mean temperature during the observation period from early June to the end of September is about $6^{\circ} \mathrm{C}$ and the mean temperature during the rest of the year, when the site is covered with snow, is about $-8^{\circ} \mathrm{C}$ at the meteorological station of $2,860 \mathrm{~m}$ a.s.l. Precipitation is about $1,000 \mathrm{~mm}$ for the period from early June to the end of September, and annual precipitation is about 2,000 $\mathrm{mm}$ (Gifu Prefecture 1969; Yanagimachi and Ohmori 1991). Mean wind speed at $2.5 \mathrm{~m}$ height over the Pinus pumila scrub is $1.6 \mathrm{~m} / \mathrm{s}$ for the summer season from July to September (Osada et al. 2002). In the pocket of Pinus pumila scrub where our experimental site was located, wind should be less than that over the Pinus pumila scrub, and is too weak to form wind-shaped microlandforms, and small mounds and stones in the site are covered with dense vegetation in all directions.



Photo 1. View of the experimental site on Mt. Norikura (June, 1998). The site is located in a pocket of Pinus pumila scrub where alpine plant communities are distributed in mosaic over gravelly land. 




Photo 2. Example of inside in an open top chamber (OTC), showing measurement instruments of temperature and labeled plants for measurement of vegetation growth (September, 1998).

\section{Artificial warming}

Form of open top chamber (OTC) and control (CTRL) In order to make microclimate warming, an open top chamber (OTC) was used. The main body of the chamber was made of pentagonal transparent acrylic resin boards with a thickness of about $5 \mathrm{~mm}$. It was $335 \mathrm{~mm}$ in height; the top and base of trapezium were 290 $\mathrm{mm}$ and $490 \mathrm{~mm}$ long, respectively. The maximum open-top diameter, the maximum basal diameter and the height of the chamber were $470 \mathrm{~mm}, 800 \mathrm{~mm}$ and $300 \mathrm{~mm}$, respectively. Five OTCs were placed over plant communities (Photo 2). In order to compare temperatures and vegetation changes in OTC with those under the natural conditions, a square area (500 $\mathrm{mm} \times 500 \mathrm{~mm}$ each) close to each OTC was selected as the control (CTRL).

The open top chambers were set just after snow was uncovered in early June, except for the first year when they were set in mid-July, and they were removed just before snowfall in early October, every year. Thus, the observation duration was about 4 months, although the starting day and ending day of observation varied by year, depending on the snow conditions. The experimental site was covered with snow (about $3 \mathrm{~m}$ in average maximum thickness) during the period from early October to the next year's late May or early June.

All of OTCs and CTRLs were used for observation of phenology. Among five of each OTC and CTRL, three OTCs and the corresponding three CTRLs were for measurement of vegetation growth and coverage, and each of them was set at the same place through the experimental period. The remaining two OTCs and the corresponding two CTRLs were for measurement of biomass. They were moved and set at new places every year because plants in them were cut to collect.

Measuring climate Climatic conditions at the site and experimental plots of OTCs and CTRLs were recorded every hour by digital automatic meteorological measuring instruments. They measured air temperature at $1.5 \mathrm{~m}$ height, sunshine, precipitation at the site just for reference. For investigation of temperature enhancement by OTC, using sensors of StowAway Tidbit (ONSET, USA), air temperature at vegetation height $(5 \mathrm{~cm}$ high above ground) and ground temperature of root layer $(3 \mathrm{~cm}$ deep) were measured in every plot of OTCs and CTRLs. The sensor was set under a shrub at a point of $25 \mathrm{~cm}$ distance from the center of each plot. Daily mean temperature of each day was calculated as the arithmetic mean of temperatures of 24 observations and of five plots (A to E for OTC, and 1 to 5 for CTRL). For convenience to compare with vegetation growth as described later, the observation duration was divided into two terms. They are the first half term (from the first observation day of the year (early June) to the end of July) and the second half term (from the beginning of August to the last observation day of the year (early October)). The first term is characterized by rapid vegetation growth and the second term is characterized by still stand of vegetation growth. The differences of daily mean temperature between OTCs and CTRLs were examined by $t$ test with a level of significance of $5 \%$, using the mean of daily mean temperature for the observation duration, the standard deviation and the observation days.

\section{Study species}

The study species are listed as follows. The reason for choosing these plants is that they are common and dominant in and around the experimental site.

- Empetrum nigrum var. japonicam (Empe- 
traceae) (Japanese name: Gankouran) is an evergreen shrub, widespread and common in high mountainous areas. This species is dioecious.

- Carex scita (Cyperaceae) (Japanese name: Miyama ashiboso suge) is a deciduous perennial herb, found in grasslands of gravelly land in high mountainous areas.

- Loiseleuria procumbens (Ericaceae) (Japanese name: Minezuou) is an evergreen shrub, common at sunny rocky and gravelly fields of high mountainous areas.

- Vaccinium vitis-idaea var. minu (Ericaceae) (Japanese name: Kokemomo) is an evergreen shrub, widespread and common throughout the Arctic and high mountainous areas.

- Sieversia pentapetala (Rosaceae) (Japanese name: Chinguruma) is a deciduous shrub, found around snowfields, wetlands and grasslands in high mountainous areas.

- Schizocodon soldanelloides $f$. alpinus (Diapensiaceae) (Japanese name: Koiwakagami) is an evergreen perennial herb, found in grasslands and around the edge of forests and scrubs in high mountainous areas.

\section{Vegetation growth}

In order to measure vegetation growth, four species; Empetrum nigrum var. japonicam, Carex scita, Loiseleuria procumbens and Vaccinium vitis-idaea var. minu were chosen, and five samples per species were measured in each OTC (A to C) and CTRL (1 to 3). Each of OTC (A to C) and CTRL ( 1 to 3 ) was set at the same place and not moved through the experimental period from 1997 to 1999. At the start of observation in each year, 5 stems were newly selected and labeled for every species in each plot. The length from a reference point such as a junction of the lowest offshoot of each stem to the top of stem was measured with a ruler. The reference point of each stem was used through each observation year. The measurement unit was 0.5 $\mathrm{mm}$. The cumulative increment in length from the first measurement of the year is vegetation growth, and the vegetation growth of the last observation means the annual vegetation growth of the year. The increment in length during the period from the latest measurement indicates the growth rate. The differences in yearly vegetation growth between OTCs and
CTRLs are shown in Table 3.

Because some stems were damaged in the way of observation, number of observed stems for each species is finally not always 15 stems. Mean growth rate of each species was calculated as the arithmetic mean of growth rates of observed stems. Using mean growth rate, standard deviation and number of stems, the difference in mean growth rates between OTCs and CTRLs was tested by a $t$-test with a level of significance of $5 \%$.

\section{Phenology}

Phenological development of all species selected was observed in all experimental plots. On each observation day, current leaves, flowers, fruition, and coloring were ranked according to the developing stage; 1 : sign of start, 2 : in progress and 3: completion, for each phenological aspect. The criteria are as follows.

Current leaves: stage 1: one stem with foliation but other stems without leaf in the plot, stage 2: about half of the observed stems foliation but other stems with no new leaf, and stage 3: all stems with foliation.

Flowering: stage 1: one flower bud among many buds begins to burst open in the plot, stage 2: about half of the flower buds are open but others are still in bud, and stage 3: all buds have burst.

Fruition: stage 1: a small and green colored fruit appears on a stem in the plot, stage 2: many fruits increase in size and some fruits are in coloring for maturity, but others are not in coloring, stage 3: all fruits are in coloring.

Coloring of leaf: stage 1: some leaves are colored but others are green in the plot, stage 2: about half of the leaves are colored but others are still green, stage 3: all leaves on the stems are colored, though some leaves have fallen.

Wilting indicates occurrence of death of leaves of Carex scita and Sieversia pentapetala due to low temperature accompanying frost. Almost all leaves were damaged by the first severe frost.

Phenology was examined by each phenological aspect. On the basis of the raw data in each plot, average stage ( 1 or 2 or 3 ) of each phenological aspect was evaluated for each OTCs and CTRLs on every observation date. Then sea- 
sonal changes in average stage of each phenological aspect were compared between OTCs and CTRLs.

\section{Biomass}

Aboveground biomass was measured in two OTCs (D and $\mathrm{E}$ ) and the corresponding two CTRLs (4 and 5). Every plot was divided into 4 square areas $(150 \mathrm{~mm} \times 150 \mathrm{~mm}$ each), and the plants standing in each square were cut with scissors to collect. The collected plants were dried in shade for 1 week or longer. Raw data of the dry weight of 8 square areas for each OTC and CTRL were averaged. Difference in average dry weight between OTCs and CTRLs was calculated for each year. Then, the results were analyzed to check for any difference between them. Because the set-places of OTCs and CTRLs for biomass measurement were moved every year, the biomass is not of integrated years for the experimental period but is of every one year.

\section{Plant coverage}

Change in plant community may be expressed by the change in species composition in a community. The species composition is often expressed by ratios of stem number or coverage of individual species to all species existing in the unit area. For the community with one shrub layer such as an alpine plant community surveyed in this research, changes in coverage of individual species in the unit area is an important and representative index expressing change in vegetation. The change in coverage might indicate that vegetation change with alternation of species has been in process.

The area covered with each species was sketched using a color felt-tip pen on a transparent acrylic resin board $(300 \mathrm{~mm} \times 300 \mathrm{~mm})$ put on the experimental plots (OTC -A, B, C; CTRL $-1,2,3$ ) on the last experimental day of the year. This was done every experimental year using the same board for each plot, but using different colors to avoid confusion. Then the change in coverage of each species was analyzed for each plot and compared between OTCs and CTRLs to find which species had increased or diminished in coverage.

\section{Results}

This section describes only the experimental results, and their ecological and/or environmental meanings will be discussed in the following section.

\section{Climate}

Air temperatures at vegetation height $(5 \mathrm{~cm}$ above ground) (Table 1) Mean of daily mean air temperatures during the observation duration (June to October) were $11.13^{\circ} \mathrm{C}$ (1997), $12.47^{\circ} \mathrm{C}(1998)$ and $12.43^{\circ} \mathrm{C}(1999)$ in OTCs, and those in CTRLs were $10.55^{\circ} \mathrm{C}(1997), 11.73^{\circ} \mathrm{C}$ (1998) and $11.79^{\circ} \mathrm{C}(1999)$, respectively. The differences of daily mean air temperatures between OTCs and CTRLs were $0.57^{\circ} \mathrm{C}$ (1997), $0.74^{\circ} \mathrm{C}(1998)$ and $0.64^{\circ} \mathrm{C}(1999)$, respectively (Table 1). The differences are all significant for the $t$-test at the $5 \%$ level. For terms; the first half and the second half, differences between OTCs and CTRLs were in the range from $0.5^{\circ} \mathrm{C}$ to $1.0^{\circ} \mathrm{C}$, and all of them were also significant for the $t$-test at the $5 \%$ level (Table 1). Average of temperature enhancement was $0.65^{\circ} \mathrm{C}$ through the experimental period. Using five days run-

Table 1. Differences in mean air and ground temperatures between OTCs and CTRLs $\left({ }^{\circ} \mathrm{C}\right)$

\begin{tabular}{|c|c|c|c|c|c|c|}
\hline \multirow{2}{*}{$\frac{\text { Location }}{\text { Term }}$} & \multicolumn{3}{|c|}{ Air (5 cm height) } & \multicolumn{3}{|c|}{ Ground (3 cm depth) } \\
\hline & 1st half & 2nd half & whole & 1st half & 2nd half & whole \\
\hline Month & 6,7 & $8,9,10$ & $6-10$ & 6,7 & $8,9,10$ & $6-10$ \\
\hline 1997 & 0.52 & 0.60 & 0.57 & 0.15 & 0.36 & 0.28 \\
\hline 1998 & 0.96 & 0.56 & 0.74 & 0.50 & 0.25 & 0.36 \\
\hline 1999 & 0.60 & 0.67 & 0.64 & 0.10 & 0.11 & 0.11 \\
\hline Mean & 0.69 & 0.61 & 0.65 & 0.25 & 0.24 & 0.25 \\
\hline
\end{tabular}

Difference $=\mathrm{T}_{\text {OTCs }}-\mathrm{T}_{\mathrm{CTRLS}}\left({ }^{\circ} \mathrm{C}\right)$.

The differences are all significant at the $5 \%$ level. 


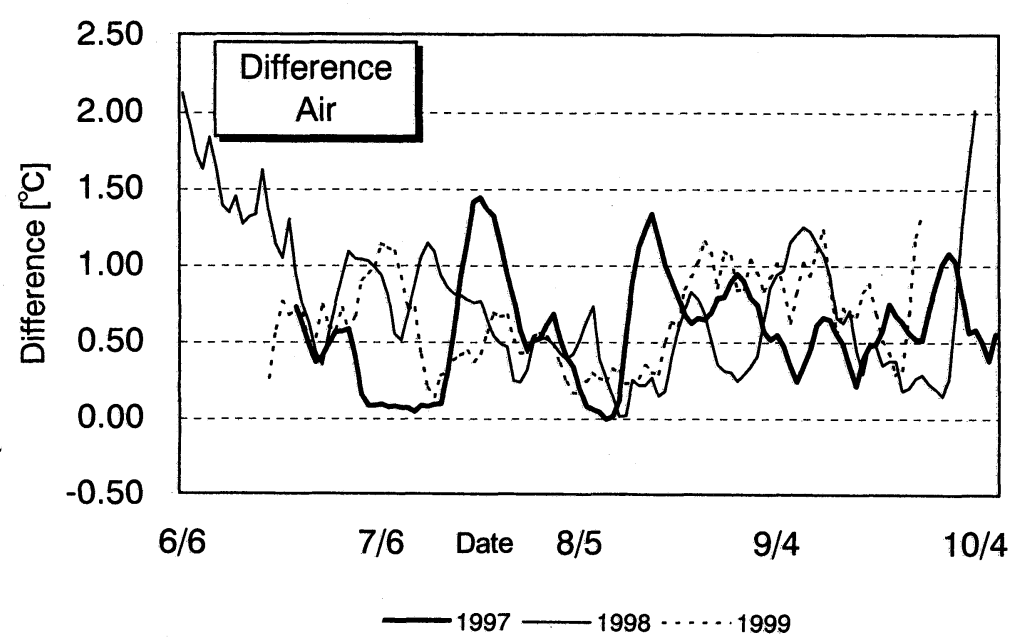

Figure 2. Seasonal changes of difference in mean air temperature at vegetation height between OTCs and CTRLs.

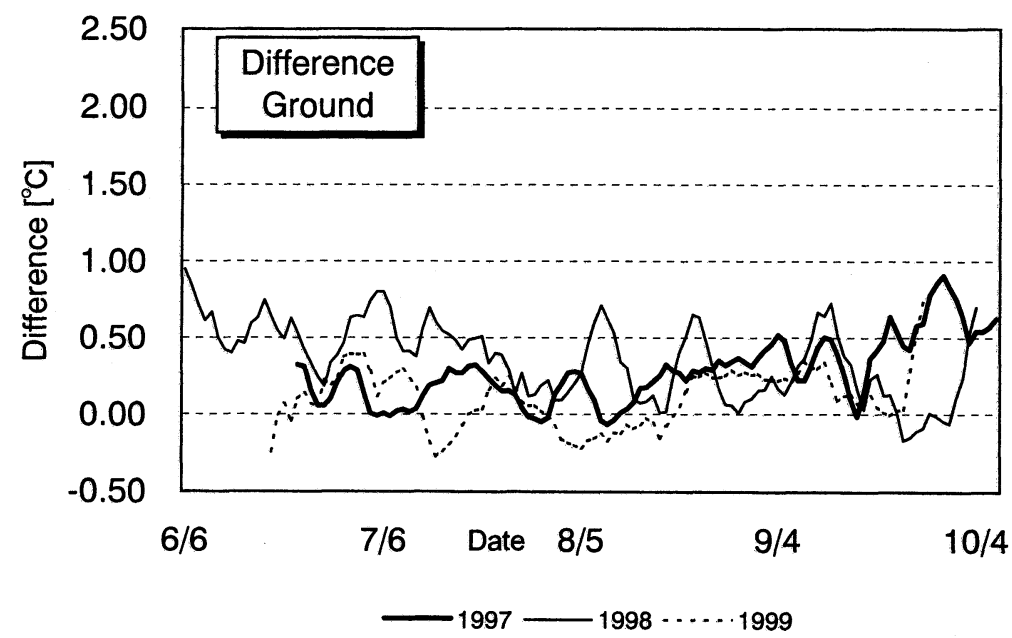

Figure 3. Seasonal changes of difference in mean ground temperature at $3 \mathrm{~cm}$ depth between OTCs and CTRLs.

ning mean, seasonal changes in difference of daily air temperature between OTCs and CTRLs are shown in Figure 2. They show cycle-like fluctuations with an interval of several days. The range is from 0 to about $1.5^{\circ} \mathrm{C}$. There is no conspicuous difference in fluctuation between the first half term and second half term for every year, although the fluctuations may depend on weather conditions; fine, cloudy, rainy and windy days.

Ground temperatures at root layer $(3 \mathrm{~cm}$ depth) (Table 1) Mean daily ground temperatures in OTCs were $10.88^{\circ} \mathrm{C}(1997), 11.70^{\circ} \mathrm{C}$
(1998) and $11.89^{\circ} \mathrm{C}(1999)$, and those in CTRLs were $10.60^{\circ} \mathrm{C}(1997), 11.34^{\circ} \mathrm{C}(1998)$ and $11.79^{\circ} \mathrm{C}$ (1999), respectively. The differences of mean daily ground temperatures between OTCs and CTRLs were $0.28^{\circ} \mathrm{C}(1997), 0.36^{\circ} \mathrm{C}(1998)$ and $0.11^{\circ} \mathrm{C}$ (1999) (Table 1). The differences are all significant for the $t$-test at the $5 \%$ level. For terms; the first half and the second half, differences between OTCs and CTRLs were in the range from $0.1^{\circ} \mathrm{C}$ to $0.5^{\circ} \mathrm{C}$, and all of them were also significant for the $t$-test at the $5 \%$ level (Table 1). Average of temperature enhancement was $0.25^{\circ} \mathrm{C}$ through the observation pe- 
Table 2. Seasonal changes in vegetation growth, growth rate and

\begin{tabular}{|c|c|c|c|c|c|c|c|c|c|c|c|c|}
\hline \multirow{3}{*}{$\begin{array}{c}\text { Species } \\
\text { Obser. date }\end{array}$} & \multicolumn{6}{|c|}{ Empetrum nigrum } & \multicolumn{6}{|c|}{ Carex scita } \\
\hline & \multicolumn{3}{|c|}{ Growth } & \multicolumn{3}{|c|}{ Growth rate } & \multicolumn{3}{|c|}{ Growth } & \multicolumn{3}{|c|}{ Growth rate } \\
\hline & OTCs & CTRLs & Dif. & OTCs & CTRLs & Dif. & OTCs & CTRLs & Dif. & OTCs & CTRLs & Dif. \\
\hline July 7,1997 & 0.0 & 0.0 & 0.0 & 0.0 & 0.0 & 0.0 & 0.0 & 0.0 & 0.0 & 0.0 & 0.0 & 0.0 \\
\hline August 14 & 1.3 & 0.6 & 0.7 & 1.3 & 0.6 & 0.7 & 14.6 & 12.4 & 2.2 & 14.6 & 12.4 & 2.2 \\
\hline Sept. 13 & 2.0 & 0.5 & 1.5 & 0.7 & -0.1 & 0.8 & 15.2 & 13.0 & 2.2 & 0.6 & 0.6 & 0.0 \\
\hline October 9 & 2.0 & 0.5 & 1.5 & 0.0 & 0.0 & 0.0 & 15.2 & 13.0 & 2.2 & 0.0 & 0.0 & 0.0 \\
\hline Jun & 0 & 0. & 0 & 0. & 0. & 0.0 & 0.0 & 0.0 & 0.0 & 0.0 & 0.0 & 0.0 \\
\hline June 29 & 5.6 & 0.4 & 5.2 & 5.6 & 0.4 & 5.2 & 103.0 & 60.7 & 42.3 & 103.0 & 60.7 & 42.3 \\
\hline August 1 & ND & ND & ND & ND & ND & ND & ND & ND & ND & ND & ND & ND \\
\hline Sept. 1 & 8.0 & 2.0 & 6.0 & 2.4 & 1.6 & 0.8 & 187.6 & 82.2 & 105.4 & 84.6 & 21.5 & 63.1 \\
\hline October 10 & 8.0 & 1.6 & 6.4 & 0.0 & -0.4 & 0.4 & 185.6 & 81.0 & 104.6 & -2.0 & -1.2 & -0.8 \\
\hline June 17,1999 & 0.0 & 0.0 & 0.0 & 0.0 & 0.0 & 0.0 & 0.0 & 0.0 & 0.0 & 0.0 & 0.0 & 0.0 \\
\hline July 16 & 2.9 & 2.1 & 0.8 & 2.9 & 2.1 & 0.8 & 135.9 & 56.8 & 79.1 & 135.9 & 56.8 & 79.1 \\
\hline August 9 & 8.5 & 5.5 & 3.0 & 5.6 & 3.4 & 2.2 & 184.7 & 76.5 & 108.2 & 48.8 & 19.7 & 29.1 \\
\hline Sept. 3 & 9.4 & 6.1 & 3.3 & 0.9 & 0.6 & 0.3 & 186.4 & 75.9 & 110.5 & 1.7 & -0.6 & 2.3 \\
\hline Sept. 29 & 9.9 & 6.2 & 3.7 & 0.5 & 0.1 & 0.4 & 182.5 & 75.8 & 106.7 & -3.9 & -0.1 & -3.8 \\
\hline
\end{tabular}

Growth: cumulative increment in length from the first measurement of the year. Growth rate: increment in length during the period from the last measurement. Dif.: Difference between OTCs and CTRLs (=OTCs-CTRLs), ND: No data.

Table 3. Annual vegetation growth and differences between OTCs and CTRLs (mm)

\begin{tabular}{|c|c|c|c|c|c|c|c|c|c|c|c|c|}
\hline \multirow[t]{2}{*}{ Species } & \multicolumn{3}{|c|}{ Empetrum nigrum } & \multicolumn{3}{|c|}{ Carex scita } & \multicolumn{3}{|c|}{ L. procumbens } & \multicolumn{3}{|c|}{ Vaccinium vitis-idaea } \\
\hline & OTCs & CTRLs & Dif. & OTCs & CTRLs & Dif. & OTCs & CTRLs & Dif. & OTCs & CTRLs & Dif. \\
\hline 1997 & 2.0 & 0.5 & 1.5 & 15.2 & 13.0 & 22 & 2.4 & 0.9 & 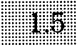 & 1.0 & 1.2 & -0.2 \\
\hline 1998 & 8.0 & 1.6 & 64 & 185.6 & 81.0 & 104.6 & 1.8 & -0.3 & 2.11) & 0.4 & -0.3 & 0.7 \\
\hline 1999 & 9.9 & 6.2 & 3.7 & 182.5 & 75.8 & 106.7 & 5.2 & 3.1 & 2.1) & 6.5 & 1.5 & (5) \\
\hline
\end{tabular}

Dif.: Difference (=OTCs-CTRLs).

: Significant at the $5 \%$ level.

riod. Using five days running mean, the seasonal changes in difference of ground temperature between OTCs and CTRLs are shown in Figure 3. They show cycle-like fluctuations with an interval of several days similar to those of the air temperature described above, although the range is less, from 0 to about $1.0^{\circ} \mathrm{C}$, than that of the air temperature. There is also no conspicuous difference in fluctuation between the first half term and the second half term for every year.

\section{Vegetation growth}

The results of measurement at each observed day are shown in Table 2. The growth indicates the cumulative increment in length from the first measurement in each year, and the growth rate indicates the increment in length during the period from the last measurement. The differences in annual vegetation growth between OTCs and CTRLs are shown in Table 3. The differences in vegetation growth between OTCs and CTRLs were significant for the $t$-test at the 5\% level, except for those of Vaccinium vitis-idaea in 1997 and 1998 (Table 3). Seasonal changes in vegetation growth are shown in Figures $4 \mathbf{a}, \mathbf{b}, \mathbf{c}$ and $\mathbf{d}$, for each species.

Empetrum nigrum (Figure 4a) Empetrum nigrum is the most dominant species in and around the experimental site. In 1997, the experimental period was three months due to the late start of measurement in mid July. Vegetation growth was only $2.0 \mathrm{~mm}$ in OTCs and $0.5 \mathrm{~mm}$ in CTRLs. However, the difference between 
differences between OTCs and CTRLs for each year ( $\mathrm{mm}$ )

\begin{tabular}{|c|c|c|c|c|c|c|c|c|c|c|c|}
\hline \multicolumn{6}{|c|}{ Loisereuria procumbens } & \multicolumn{6}{|c|}{ Vaccinium vitis-idaea } \\
\hline \multicolumn{3}{|c|}{ Growth } & \multicolumn{3}{|c|}{ Growth rate } & \multicolumn{3}{|c|}{ Growth } & \multicolumn{3}{|c|}{ Growth rate } \\
\hline OTCs & CTRLs & Dif. & OTCs & CTRLs & Dif. & OTCs & CTRLs & Dif. & OTCs & CTRLs & Dif. \\
\hline 0.0 & 0.0 & 0.0 & 0.0 & 0.0 & 0.0 & 0.0 & 0.0 & 0.0 & 0.0 & 0.0 & 0.0 \\
\hline 0.3 & 0.2 & 0.1 & 0.3 & 0.2 & 0.1 & 0.2 & 0.0 & 0.2 & 0.2 & 0.0 & 0.2 \\
\hline 2.4 & 0.9 & 1.5 & 2.1 & 0.7 & 1.4 & 1.0 & 1.2 & -0.2 & 0.8 & 1.2 & -0.4 \\
\hline 2.4 & 0.9 & 1.5 & 0.0 & 0.0 & 0.0 & 1.0 & 1.2 & -0.2 & 0.0 & 0.0 & 0.0 \\
\hline 0.0 & 0.0 & 0.0 & 0.0 & 0.0 & 0.0 & 0.0 & 0.0 & 0.0 & 0.0 & 0.0 & 0.0 \\
\hline 1.0 & -0.3 & 1.3 & 1.0 & -0.3 & 1.3 & 0.6 & 0.0 & 0.6 & 0.6 & 0.0 & 0.6 \\
\hline ND & ND & ND & ND & $\mathrm{ND}$ & ND & ND & ND & ND & ND & ND & ND \\
\hline 1.9 & -0.2 & 2.1 & 0.9 & 0.1 & 0.8 & 1.0 & 0.0 & 1.0 & 0.4 & 0.0 & 0.4 \\
\hline 1.8 & -0.3 & 2.1 & -0.1 & -0.1 & 0.0 & 0.4 & -0.3 & 0.7 & -0.6 & -0.3 & -0.3 \\
\hline 0.0 & 0.0 & 0.0 & 0.0 & 0.0 & 0.0 & 0.0 & 0.0 & 0.0 & 0.0 & 0.0 & 0.0 \\
\hline 0.6 & 0.9 & -0.3 & 0.6 & 0.9 & -0.3 & 1.3 & 0.0 & 1.3 & 1.3 & 0.0 & 1.3 \\
\hline 4.7 & 2.9 & 1.8 & 4.1 & 2.0 & 2.1 & 6.7 & 1.8 & 4.9 & 5.4 & 1.8 & 3.6 \\
\hline 5.1 & 3.0 & 2.1 & 0.4 & 0.1 & 0.3 & 6.8 & 1.9 & 4.9 & 0.1 & 0.1 & 0.0 \\
\hline 5.2 & 3.1 & 2.1 & 0.1 & 0.1 & 0.0 & 6.5 & 1.5 & 5.0 & -0.3 & -0.4 & 0.1 \\
\hline
\end{tabular}

a: Empetrum nigrum



c: Loiserearia procumbens

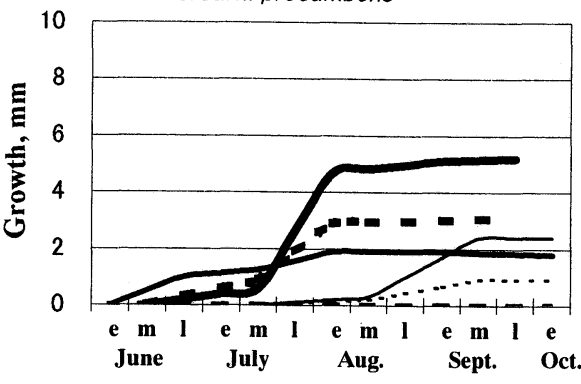

— OTC 1997

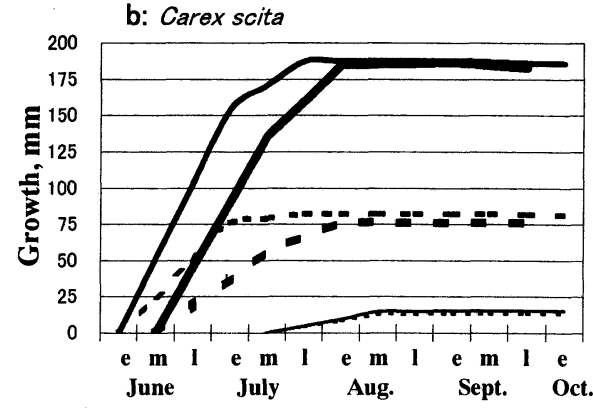

d: Vaccinium vitis-idaea

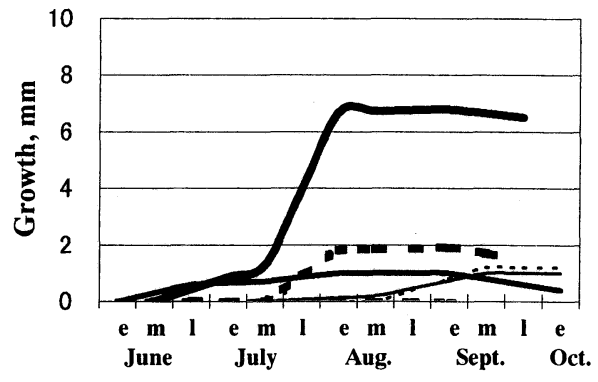

OTC 1998

CTRL1997

... CTRL1998

Figure 4. Vegetation growth in OTCs and CTRLs of a: Empetrum nigrum, b: Carex scita, c: Loiseleuria procumbens, and d: Vaccinium vitis-idaea.

OTCs and CTRLs was significant for the $t$-test at the 5\% level (Table 3). In 1998, difference in vegetation growth between OTCs and CTRLs was $6.4 \mathrm{~mm}$. In 1999, difference in vegetation growth between OTCs and CTRLs was $3.7 \mathrm{~mm}$.

Carex scita (Figure 4b) Carex scita is a deciduous perennial herb with a high growth rate of about $15-20 \mathrm{~cm}$ a year. On the first observa- 
tion day of the year, budding has started and the stems were around $2-5 \mathrm{~cm}$ in length. In 1997, due to the late start of measurement, difference in vegetation growth between OTCs and CTRLs was only $2.2 \mathrm{~mm}$. Differences in vegetation growth between OTCs and CTRLs was $105 \mathrm{~mm}$ in 1998 and $110 \mathrm{~mm}$ in 1999 .

Loisereuria procumbens (Figure 4c) Loisereuria procumbens is the second dominant species next to Empetrum nigrum in and around the experimental site. In 1997, difference in vegetation growth between OTCs and CTRLs was only $1.5 \mathrm{~mm}$. In 1998, vegetation growth in OTCs was $1.8 \mathrm{~mm}$, while samples in CTRLs never grew and reduced in length, $-0.3 \mathrm{~mm}$ due to withering of some stem tops by frost. The difference was $2.1 \mathrm{~mm}$ for the calculation. In 1999, difference in vegetation growth between OTCs and CTRLs was $2.1 \mathrm{~mm}$.

Vaccinium vitis-idaea (Figure 4d) Vaccinium
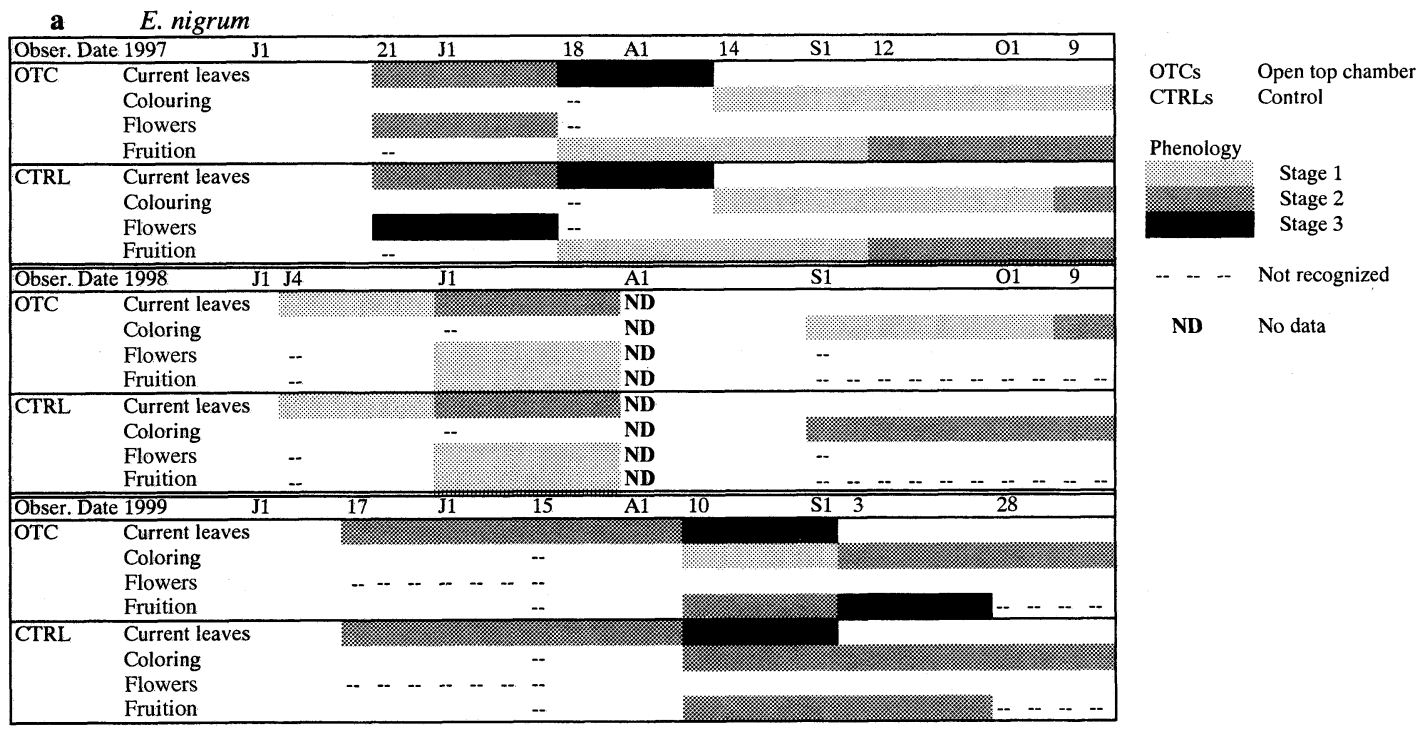

-- -- - Not recognized

ND No data

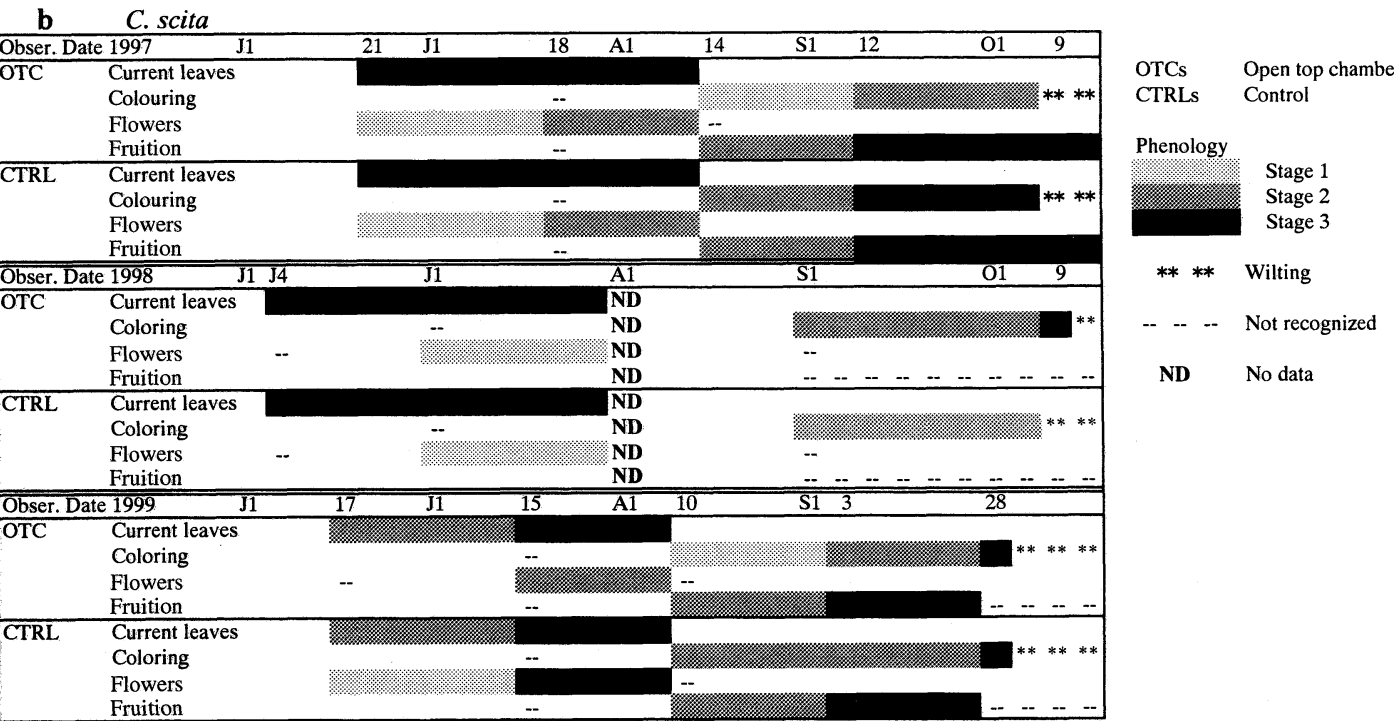

Figure 5. Phenological changes in OTCs and CTRLs of a: Empetrum nigrum., b: Carex scita, c: Loiseleuria procumbens, d: Vaccinium vitis-idaea, e: Sieversia pentapetala, and f: Schizocodon soldanelloides f. alpinus (Continued). 


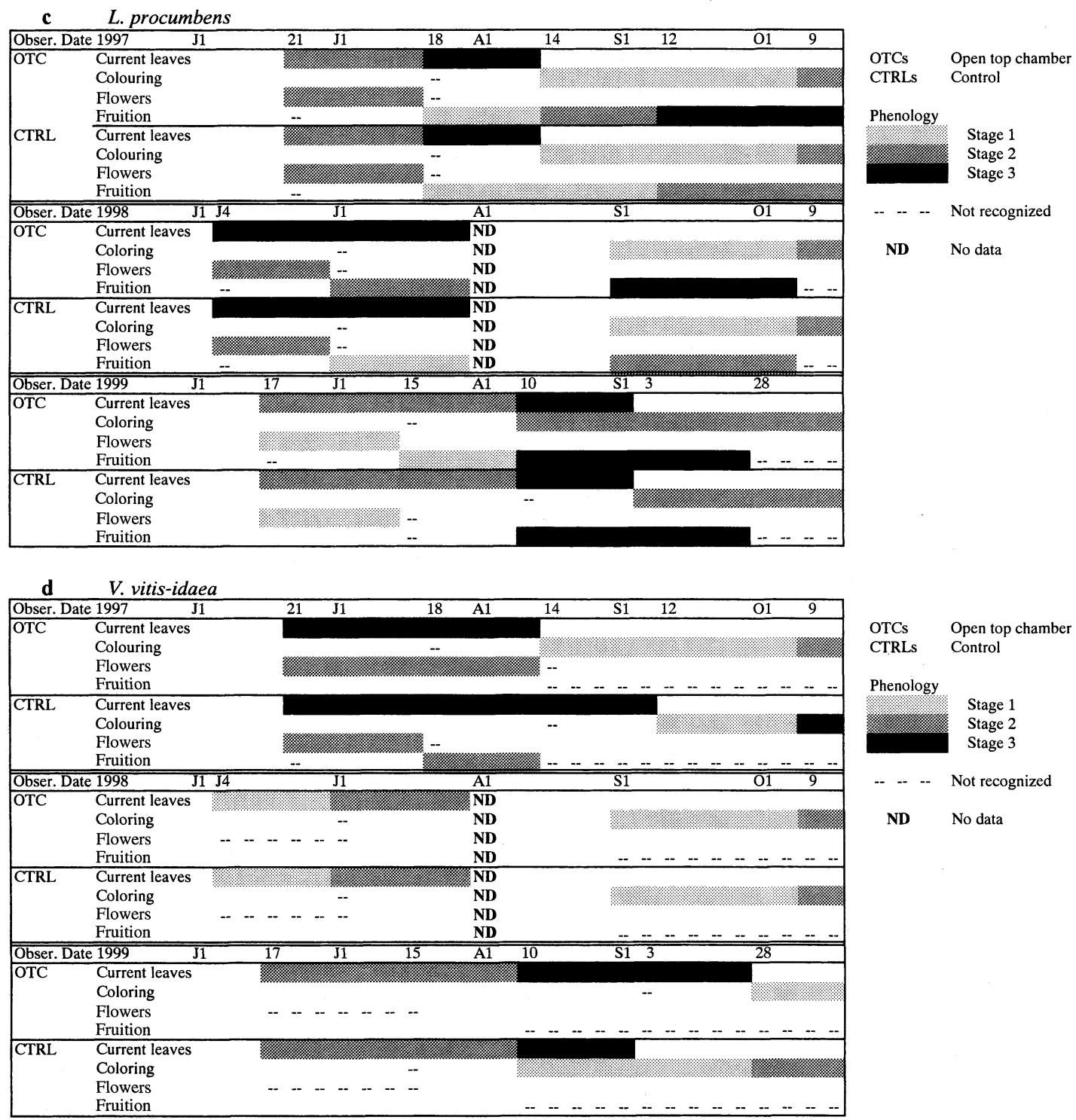

Figure 5. Phenological changes in OTCs and CTRLs of a: Empetrum nigrum., b: Carex scita, c: Loiseleuria procumbens, d: Vaccinium vitis-idaea, e: Sieversia pentapetala, and f: Schizocodon soldanelloides f. alpinus (Continued).

vitis-idaea is commonly found but is not so dense in and around the experimental site. In 1997, difference in vegetation growth between OTCs and CTRLs was $-0.2 \mathrm{~mm}$, indicating that samples in OTCs grew less than those in CTRLs. In 1998, vegetation growth in OTCs was $0.4 \mathrm{~mm}$, while samples in CTRLs never grew, showing $-0.3 \mathrm{~mm}$ for measurement. The differences in 1997 and 1998 were not significant. In 1999, vegetation growth in OTCs was $6.5 \mathrm{~mm}$, and that in CTRLs was $1.5 \mathrm{~mm}$. The difference was significant (Table 3).

\section{Phenology}

Phenology of individual species is shown in Figures $5 \mathbf{a}, \mathbf{b}, \mathbf{c}, \mathbf{d}, \mathbf{e}$ and $\mathbf{f}$. Conspicuous differences in phenology between OTCs and CTRLs are as follows.

Empetrum nigrum (Figure 5a) In 1997, on 21 June, flowers in OTCs were in stage 2, while 


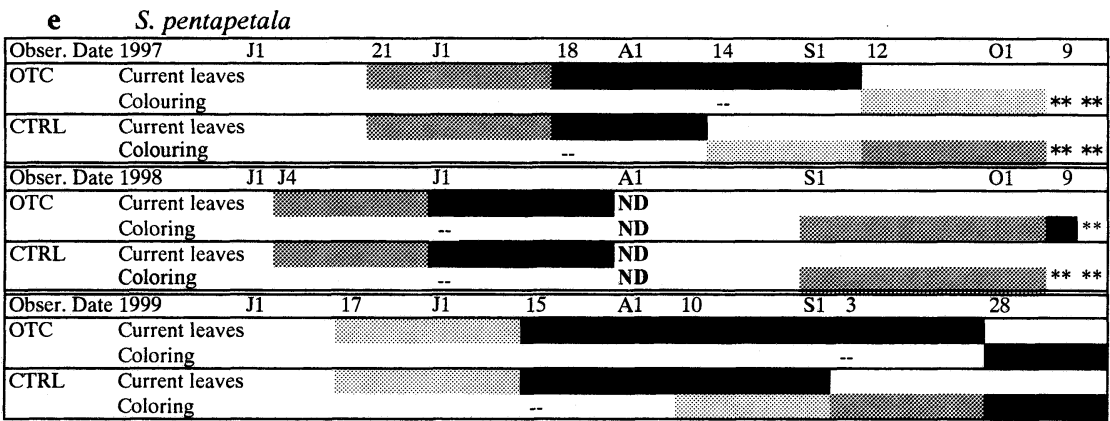

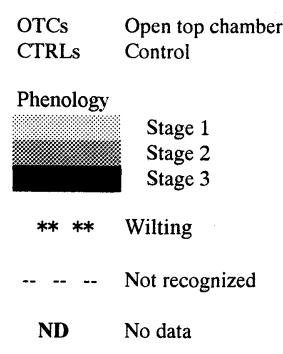



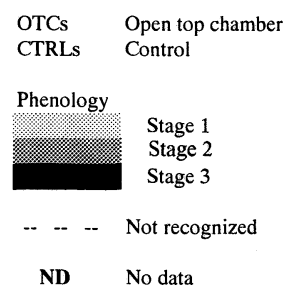

Figure 5. Phenological changes in OTCs and CTRLs of a: Empetrum nigrum., b: Carex scita, c: Loiseleuria procumbens, d: Vaccinium vitis-idaea, e: Sieversia pentapetala, and f: Schizocodon soldanelloides f. alpinus.

those in CTRLs were in stage 3. On 9 October, coloring in OTCs was still in stage 1, while that in CTRLs was in stage 2. In 1998, on 1 September, coloring in OTCs entered stage 1 , while that in CTRLs was already in stage 2. In 1999, on 10 August, coloring in OTCs just entered stage 1 , while that in CTRLs was in stage 2 . On 3 September, fruition in OTCs was in stage 3, while that in CTRLs was still in stage 2 .

Carex scita (Figure 5b) In 1997, on 14 August, stage 1 of coloring just started in OTCs, while in CTRLs it was already in stage 2. On 12 September, coloring in OTCs as in stage 2, while that in CTRLs was in stage 3. In 1998, on 9 October, coloring was still kept in stage 3 for some samples in OTCs, while samples in CTRLs wilted. In 1999, on $15 \mathrm{July,} \mathrm{flowering} \mathrm{was} \mathrm{still}$ in stage 2 in OTCs, however, in CTRLs flowering was in stage 3 . One month later, on 10 August, coloring in OTCs entered stage 1, while that in CTRLs was already in stage 2 .
Loisereuria procumbens (Figure 5c) In 1997, on 14 August, fruition in OTCs was in stage 2, while that in CTRLs just entered stage 1. One month later, on 12 September, fruition in OTCs was in stage 3 , while that in CTRLs was in stage 2 . In 1998, on 1 July, fruition in OTCs was in stage 2, while that in CTRLs just entered in stage 1. Two months later, on 1 September, fruition in OTCs was in stage 3, while that in CTRLs was still in stage 2 . In 1999 , on 10 August, coloring in OTCs was already in stage 2, while on 3 September, coloring in CTRLs just entered in stage 1.

Vaccinium vitis-idaea (Figure 5d) In 1997, on $18 \mathrm{July}$, flowering in OTCs was still in stage 2 , while in CTRLs, fruition was in stage 2 . On 14 August, stage 1 of coloring started in OTCs, but that in CTRLs had not started yet. On 12 September, coloring in CTRLs entered stage 1, and that in OTCs were kept in stage 1 . On 9 October, coloring in OTCs was in stage 2, while 
that in CTRLs was in stage 3. In 1998, there were no differences between in OTCs and in CTRLs in terms of phenology. In 1999, on 10 August, coloring in CTRLs entered stage 1. Then on 28 September, coloring in OTCs entered in stage 1 , and that in CTRLs was in stage 2.

Sieversia pentapetala (Figure 5e) In 1997, on 14 August, coloring in CTRLs entered stage 1. Then one month later, on 12 September, coloring in OTCs entered stage 1 , while that in CTRLs was in stage 2. In 1998, on 9 October, in OTCs coloring was in stage 3 including wilted leaves, while most leaves wilted in CTRLs. In 1999, on 10 August, coloring in CTRLs entered stage 1. Then on 3 September, coloring in CTRLs was in stage 2, while coloring did not start yet in OTCs. On 28 September, coloring was in stage 3 both in OTCs and CTRLs.

Schizocodon soldanelloides $f$. alpinus (Figure $5 \mathbf{f}$ ) In 1997, on 12 September, coloring in OTCs kept to stage 1 , while that in CTRLs was in stage 2. In 1998, there was no difference in phenology between OCTs and CTRLs. In 1999, on 28 September, coloring in CTRLs entered stage 3 , while that in OTCs was still in stage 2 .

\section{Biomass}

Aboveground biomasses of OTCs and CTRLs, and the differences between them are shown in Table 4. In 1997, biomass in OTCs was $17.48 \mathrm{~g} /$ $225 \mathrm{~cm}^{2}$, while that in CTRLs was $18.11 \mathrm{~g} / 225$ $\mathrm{cm}^{2}$. In 1998 , biomasses in OTCs and CTRLs were $14.22 \mathrm{~g} / 225 \mathrm{~cm}^{2}$ and $15.12 \mathrm{~g} / 225 \mathrm{~cm}^{2}$, respectively. For these two years, biomasses in OTCs were less than those in CTRLs. In 1999, biomass in OCTs, $15.37 \mathrm{~g} / 225 \mathrm{~cm}^{2}$, is larger than that in CTRLs, $14.08 \mathrm{~g} / 225 \mathrm{~cm}^{2}$. All of the differences in biomass between OTCs and CTRLs were small and not significant at the $5 \%$ level (Table 4).

\section{Plant coverage}

Examples of changes in coverage through three years are shown in Figure $6 \mathbf{a}$ by an OTC

Table 4. Differences in biomass between OTCs and CTRLs $\left(\mathrm{g} / 225 \mathrm{~cm}^{2}\right)$

\begin{tabular}{lrrr}
\hline Year & 1997 & 1998 & 1999 \\
\hline OTCs & 17.48 & 14.22 & 15.37 \\
CTRLs & 18.11 & 15.12 & 14.08 \\
OTCs-CTRLs & -0.61 & -0.90 & 1.29 \\
OTCs/CTRLs & 0.97 & 0.94 & 1.09 \\
\hline
\end{tabular}

a

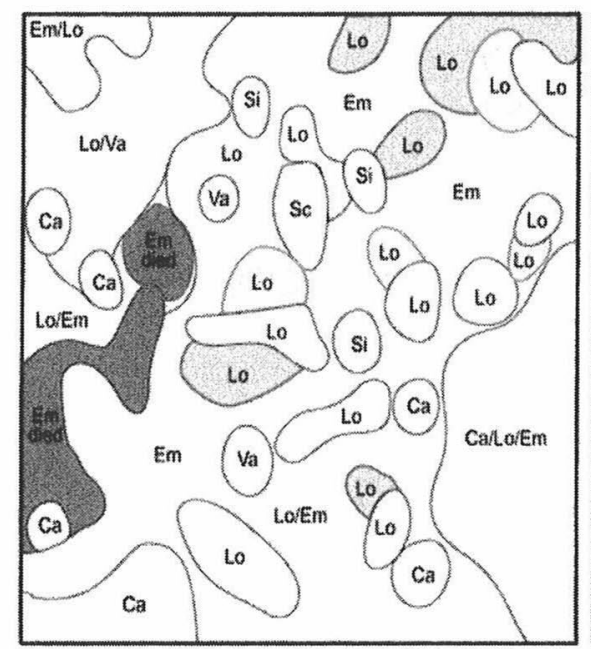

OTC-B

b

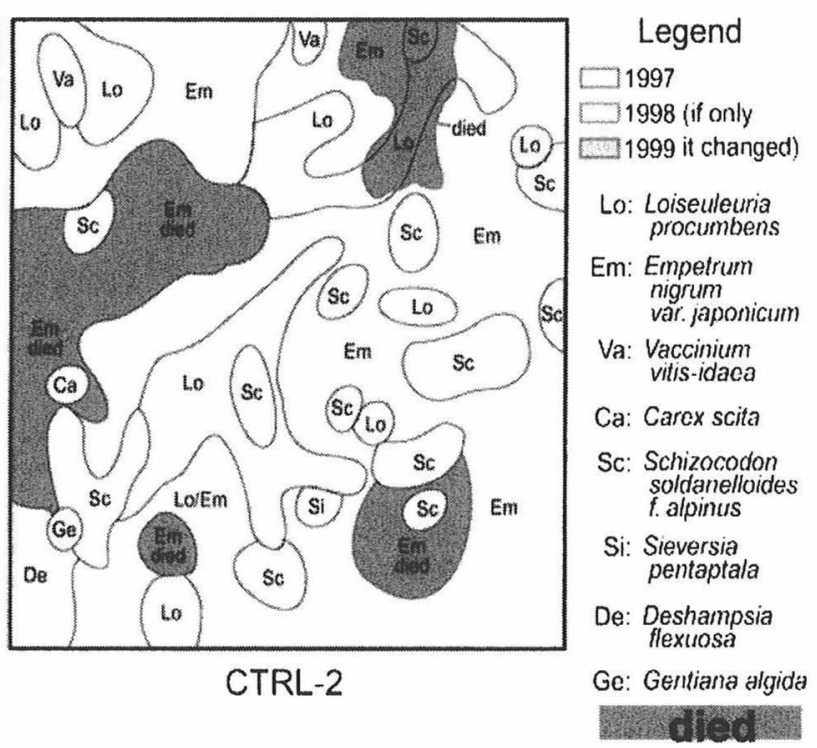

Figure 6. Change in coverage of species during the period from 1997 to 1999 . a: OTC-B and b: CTRL- 2 which is corresponding to OTC-B. 
and Figure $6 \mathbf{b}$ by the corresponding CTRL. In the first and the second year, change in coverage could not be visibly recognized. In the third year (1999), the area of Loisereuria procumbens (Lo) markedly increased in OTCs, covering the Empetrim nigrum $(\mathrm{Em})$ area (Figure 6a). The stems of $E m$ covered with $L o$ did not die, but diminished in growth. On the other hand, $E m$ in OTCs did not increase in area and some stems of $E m$ died. In CTRLs, on the contrary, Lo did not increase in coverage at all. $E m$ also did not increase in area and some stems of $E m$ also died (Figure $6 \mathbf{b}$ ). The other species observed; Carex scita, Vaccinium vitis-idaea, Sieversia pentapetala and Schizocodon soldanelloides f. alpinus, did not show any conspicuous changes in coverage even in the last experimental year. Invasion and germination of any other new species were not recognized in both OTCs and CTRLs throughout the experimental period.

\section{Discussion and Conclusions}

\section{Temperature enhancement}

Passive open top devices have been used often to enhance temperature. The results in temperature enhancement varied by as much as $1-3^{\circ} \mathrm{C}$ for air temperature at about $10 \mathrm{~cm}$ height and $2-5^{\circ} \mathrm{C}$ for ground temperature at 0 to $10 \mathrm{~cm}$ depth in the ITEX reports (Henry and Molau 1997; Marion et al. 1997). Similar result $\left(+2.8^{\circ} \mathrm{C}\right)$ for air temperature was reported from the experiments in Spitsbergen (Hodkinson et al. 1998). Degree of temperature enhancement varies by both device type and measurement height, and the day length, sunshine (cloudiness), rainfall and wind are considered to be the main natural factors controlling temperature enhancement (Marion et al. 1997). The chambers used in our experiment were pentagonal open top chambers. They were different in shape and size from those used in the ITEX project such as the ITEX corner, cone chamber, hexagon chamber and plastic tent and those used in the Spitsbergen experiments such as small polythene tents and circular cloches. Thus, it is difficult to compare exactly the results of our results with those of the experiments in the arctic areas.
The temperature enhancement, however, of the experiments in the arctic areas is higher than that of our experiment $\left(+0.65^{\circ} \mathrm{C}\right)$. The reasons for such high temperature enhancement in the arctic areas (from around $66^{\circ} \mathrm{N}$ to the North Pole) might be that the duration of sunshine is longer than that in the mid-latitude areas like Mt. Norikura (around $36^{\circ} \mathrm{N}$ ) in summer season. For example on the day of summer solstice, the day length of the edge of arctic zone is 24 hours and that of Tokyo is 14 hours 35 minutes. Secondly, the lower precipitation in arctic areas might cause the high temperature enhancement. The differences in both air and ground temperatures between chamber and control were less for rainy days than for sunny days (Marion et al. 1997). The differences in both air and ground temperatures between OTCs and CTRLs show sometimes 0 or minus values in our experiment (Figures 2 and 3). They often corresponded to rainy days. The sites of the ITEX project were occasionally arctic tussock, wet meadow tundra, polar semidesert and sub arctic dwarf shrub heath (Chapin et al. 1985; Wookey et al. 1994; Robinson et al. 1995). Precipitation of these sites is relatively low, generally lower than $100 \mathrm{~mm}$ for summer season. On the contrary, the summer season rainfall of Mt. Norikura is over 1,000 mm (Gifu Prefecture 1969; Yanagimachi and Ohmori 1991; Iguchi et al. 1998).

On the other hand, it has been pointed that wind speed has a negative impact on mean daily temperature, and that especially when mean wind speeds are higher than $4 \mathrm{~m}$, negative effect of wind on temperature enhancement is remarkable (Marion et al. 1997). At our experimental site, mean wind speed at $2.5 \mathrm{~m}$ height, over the height of Pinus pumila scrub, is $1.6 \mathrm{~m} / \mathrm{s}$ for the summer season from July to September, and wind speed is high on rainy days (Osada et al. 2002). In the pocket of the Pinus pumila scrub, wind should be less than that over the scrub. Thus, the wind might not have a great influence on temperature enhancement in our experiment. Therefore, the small temperature enhancement on Mt. Norikura in comparison with that in arctic areas might be mainly due to short day length and much rainfall. 


\section{Vegetation growth}

It is believed that the more temperature rises, the more plant grows, with the exceptions of extremely high or low temperatures that causes burning and freezing. Some researchers reported this evidence from their experiments using open top chamber for enhancing temperature (Havström et al. 1993; Kojima et al. 1997; Wagner and Reichegger 1997). Also, according to Zhang and Welker (1996), in particular, grass is more sensitive than forb. From our experiment, in spite of a small temperature enhancement, some evidence of these idea mentioned above were confirmed and also new evidence has been discovered. They are summarized below.

(1) Vegetation growth is significantly affected by temperature enhancement for most of the plants observed (Table 3). Both air and ground temperatures were higher in OTCs than in CTRLs. On the basis of the $t$ values (Table 1), the differences of mean daily air temperature are remarkably larger than those of mean daily ground temperature. Thus, the air temperature enhancement might have a greater influence on vegetation growth than the ground temperature enhancement.

(2) Plants grow markedly during June and July. They are still stand in growth during August and September (Figures $4 \mathbf{a}-\mathbf{d}$ ). The differences in vegetation growth rate between OTCs and CTRLs were summarized for the early period and the later period of the observa- tion period of each year (Table 5). The early period and the later period correspond approximately to the first half term and the second half term for temperature, respectively. Table 5 shows that the seasonal changes in growth rate were larger in the first half (during June and July) than in the second half (from August to October), in spite of the same degree of temperature enhancement for both terms (Table 1). Thus, it can be said that effect of temperature enhancement on vegetation growth appeared remarkably during June and July; that is, during the period from early spring to summer, for our experiment. During the second half, plants do not grow conspicuously both in OTCs and CTRLs. Especially in 1997, due to the late start of measurement in mid-July, the differences in growth rate between OTCs and CTRLs were markedly small in comparison with those in the second and third years (Table 5), even if the results of $t$-test for the differences were significant for all the species observed (Table 3).

It has been pointed that the extension of growth period affects plant growth (Zhang and Welker 1996; Suzuki and Kudo 1997; Fukuyo et al. 1998). On the basis of our observation, however, the temperature enhancement from early spring to early summer is the most effective for vegetation growth rather than the extension of growth period. From the phenological aspect, leaf coloring started generally earlier in CTRLs than in OTCs. For example, Empetrum nigrum in CTRLs showed the stage 2 of coloring even in August, 1999, while the coloring showed the

Table 5. Vegetation growth rate and differences between OTCs and CTRLs (mm) during the early period and the later one of the observation period in each year

\begin{tabular}{|c|c|c|c|c|c|c|c|c|c|c|c|c|}
\hline \multirow{2}{*}{$\frac{\text { Species }}{1997}$} & \multicolumn{3}{|c|}{ E. nigrum } & \multicolumn{3}{|c|}{ C. scita } & \multicolumn{3}{|c|}{ L. procumbens } & \multicolumn{3}{|c|}{ V. vitis-idaea } \\
\hline & OTCs & CTRLs & Dif. & OTCs & CTRLs & Dif. & OTCs & CTRLs & Dif. & OTCs & CTRLs & Dif. \\
\hline July-Aug. 14 & 1.3 & 0.6 & 0.7 & 14.6 & 12.4 & 2.2 & 0.3 & 0.2 & 0.1 & 0.2 & 0.0 & 0.2 \\
\hline Aug. 14-Oct. 9 & 0.7 & -0.1 & 0.8 & 0.6 & 0.6 & 0.0 & 2.1 & 0.7 & 1.4 & 0.8 & 1.2 & -0.4 \\
\hline 1998 & OTCs & CTRLs & Dif. & OTCs & CTRLs & Dif. & OTCs & CTRLs & Dif. & OTCs & CTRLs & Dif. \\
\hline June 4-June 29 & 5.6 & 0.4 & 5.2 & 103.0 & 60.7 & 42.3 & 1.0 & -0.3 & 1.3 & 0.6 & 0.0 & 0.6 \\
\hline June 29-Oct. 10 & 2.4 & 1.2 & 1.2 & 82.6 & 20.3 & 62.3 & 0.8 & 0.0 & 0.8 & -0.2 & -0.3 & 0.1 \\
\hline 1999 & OTCs & CTRLs & Dif. & OTCs & CTRLs & Dif. & OTCs & CTRLs & Dif. & OTCs & CTRLs & Dif. \\
\hline June 17-Aug. 9 & 8.5 & 5.5 & 3.0 & 184.7 & 76.5 & 108.2 & 4.7 & 2.9 & 1.8 & 6.7 & 1.8 & 4.9 \\
\hline Aug. 9-Sept. 29 & 1.4 & 0.7 & 0.7 & -2.2 & -0.7 & -1.5 & 0.5 & 0.2 & 0.3 & -0.2 & -0.3 & 0.1 \\
\hline
\end{tabular}

Growth rate: increment in length during the period.

Dif.: Difference (=OTCs-CTRLs). 
stage 1 in OTCs (Figure 5a). Carex scita in CTRLs was also in the stage 2 of coloring in August, 1997 and 1999 (Figure 5b), indicating the more progressed stage than that in OTCs. These indicate that the plants in CTRLs were already less vital than those in OTCs in August, and suggest that the remarkable difference in vegetation growth between OTCs and CTRLs during the period from early spring to early summer was due to the accelerated photosynthesis by temperature enhancement in OTCs in the period. For the later period after August, fruition of some species in OTCs advanced rather than that in CTRLs as shown by Empetrum nigrum in 1999 (Figure 5a) and Loisereuria procumbens in 1997 (Figure 5c). These suggest that vegetation growth became less, resulting in less difference in growth rate between OTCs and CTRLs, due to the alteration in usage of photosynthetic production from stem growth to fruit production. The effect of growth period extension on vegetation growth for the next year can not be examined at this time, although phenology is surely affected by the extension of growth period as discussed in the later section.

(3) The responses in terms of vegetation growth by temperature enhancement varied among species. Carex scita (herb) showed remarkably positive responses. On the basis of the ratio of growth to standard stem length of species, Loisereuria procumbens responded more positively than Empetrum nigrum. Vaccinium vitis-idaea did not always show positive responses, indicating unstable response to warming.

(4) Wind protection effect by the chamber on vegetation growth might be negligible for our experiment. Because the experimental site was set in a pocket of Pinus pumila scrub, wind was potentially weak. Then, a serious difference in wind speed could not occur between OTCs and CTRLs. In high altitude areas of Mt. Norikura, plants in wind-blown areas are certainly shorter than those in less windy areas for all species, pointing to the fact that strong wind may have a negative impact on vegetation growth (e.g. Marion et al. 1997). Vaccinium vitis-idaea in CTRLs, however, grew larger than in OTCs in 1997 (Figure 4d), suggesting that the physical impact of wind on vegetation growth was weak at our experimental site.

An experiment for investigation of wind effect on alpine plants was conducted in windblown alpine areas on Mt. Kiso-komagatake (2,956 $\mathrm{m}$ a.s.1.) in the Central Japanese Alps, 40 $\mathrm{km}$ southeast from Mt. Norikura (Fukuyo et al. 1998). Five wind-shields, whose shape and size are similar to the ITEX corner, were set on wind-blown alpine dwarf shrub communities. The experiment showed that mean vegetation height temperature, mean soil temperature and mean relative humidity in wind-shield plots were not seriously different from those in controls. And the results indicate that there was no significant difference in vegetation growth for mat-shaped growth forms of plants such as Diapensia lapponica (Diapensiaceae) between wind-shield plots and controls. It indicates that the wind protection by the chamber does not significantly affect vegetation growth.

\section{Phenology}

Phenological studies have been conducted by many researchers in tundra areas (e.g. Molau and Shaver 1997; Welker et al. 1997) and in alpine areas (e.g. Alatato and Totland 1997; Wagner and Reichegger 1997). In Japan, only a few researches have been performed (e.g. Nakashinden et al. 1997; Fukuyo et al. 1998; Wada et al. 1998; Iguchi et al. 1998). They showed positive effects of warming on phenology. The results, however, were not always positive. Some negative results have been reported (Stenström et al. 1997). In our experiment, under small temperature enhancement, some positive and negative results were obtained. They were summarized as follows.

(1) All of the species observed postponed both starting and ending of leaf coloring under temperature enhancement.

(2) Empetrum nigrum showed that fruition was sometimes progressed more under warming condition. It corresponds to the more progressed flowering in OTCs than in CTRLs. Vaccinium vitis-idaea, however, showed that sometimes fruition was less progressed. It should be due to the prolonged flowering in OTCs than in CTRLs. Loiseleuria procumbens produced more fruits under temperature enhancement. It might have resulted from the number of flowers 
increased by warming.

(3) For Carex scita and Sieversia pentapetala, which are deciduous species, wilting occurred at any stage of current leaves both in OTCs and CTRLs.

From the results mentioned above, it can be concluded that all species keep green leaves for longer period by temperature enhancement. It indicates that the period of photosynthesis and nutrition extends. For deciduous plants, however, when severe cold climate attacks them, wilting occurs at any stage of current leaves. Increase in production of fruits might be due to the physiological activities accelerated by temperature enhancement.

\section{Biomass}

Biomass in OTCs was less than that in CTRLs in 1997 and 1998, while in 1999, biomass in OTC was larger than that in CTRLs. Differences in biomass between OTCs and CTRLs were small for all years and not significant (Table 4). For biomass changes in warming experiment, some positive results were reported (e.g. Molgard and Christensen 1997; Welker et al. 1997). In those cases, however, the shoot height of one species was measured. In our research, however, total aboveground biomass per unit area was measured because biomass should be the total weight of the living components (in this case, plants) in an ecosystem at any moment, usually expressed as dry weight of all plants in unit area (Allaby 1992).

In arctic tundra, some species increased in growth while other species reduced in growth, and total production (biomass) remained the same under modified environmental conditions (Chapin et al. 1995). It was pointed out that the conditions favorable for some species are less favorable for other species, and that low nutrient level available to plants in tundra might constrain primary production. In Tibetan alpine tundra, dry weights of individual life forms such as grass, sedge and forb were measured and their seasonal changes were examined (Zhang and Welker 1996). It showed that differences in dry weight between minigreenhouses and controls varied with life form, and that biomass was not different between warmed and control conditions. It was considered that warmer conditions in soils might have elevated soil mineralization and increased nutrient pools available to plants, and that the ability to acquire nutrients in a competitive setting varies by life forms with different sensitivity to temperature (Zhang and Welker 1996).

As described above, it is considered that vegetation growth and biomass are regulated with the quantity and quality of nutrients at the areas of poor soils. Our experimental site was located on gravelly land with thin soil layer less than $3-5 \mathrm{~cm}$ on a high volcanic mountain. Water of springs maintained by shallow groundwater coming from the areas surrounding the experimental site shows an extremely low content of dissolved ions. Average ion concentration of $\mathrm{Na}^{+}, \mathrm{K}^{+}, \mathrm{Ca}^{2+}, \mathrm{Mg}^{2+}, \mathrm{Cl}^{-}$, $\mathrm{NO}_{3}{ }^{-}$and $\mathrm{SO}_{4}{ }^{2-}$ in the water is less than 2.2 ppm. It is close to that of precipitation at the summit of Mt. Norikura, $0.7 \mathrm{ppm}$, and markedly less than the average ion concentration of Japanese rivers, $36.2 \mathrm{ppm}$ (Anazawa and Ohmori 2000). It indicates that the soil at the experimental site is in an extremely low nutrient condition. Enhancement of air and soil temperatures might accelerate physiological activities such as photosynthesis and nutrition for most species. Temperature enhancement, however, might be more favorable for some species like Loiseleuria procumbens and Carex scita than others, leading them to capture relatively more nutrients. It must result in deficient nutrient condition for others under a serious competition among species. Vegetation in our experimental site is in a climax phase. It indicates that the total production of plants in unit area might be the maximum according to the nutrient level of the site. At the site with a potentially low nutrient level, increase in biomass due to warming should be limited at a low level, even though ground temperature enhancement increases nutrient pools available to plants. That may be why the biomass did not show a recognizable difference between OTCs and CTRLs.

Now, we should pay attention to the fact that, because the plots for biomass measurement were moved and newly set for each experimental year, cumulative effect of warming on biomass for some yeas can not be evaluated. Effect 
of temperature enhancement on root growth also can not be analyzed on the basis of our experiment. Difference in biomass between OTCs and CTRLs might not be recognizable only for one year, if the difference is small, collecting practice is rough and measurement precision is low. Changes in coverage discussed in the next section may show the cumulative effect of warming on vegetation ecology.

\section{Plant coverage}

Studies on the change of community by experimental warming are very few. On the basis of the results from an experiment at the northern Swedish Lapland for 3 years, evergreen Cassiope tetragona had low competitive ability under a warmer condition and decreased in reproductive success by overgrowth of vigorous gramineous canopy (Molau et al. 1997). In our research, the tentative results for the changes in coverage of species under experimental warming are summarized below.

At the end of the first year experiment, any changes in coverage were not recognized. In the second year (1998), Loisereuria procumbens (Lo) showed a sign of increase in coverage in OTCs (Figure 6a), while there was no change in coverage in CTRLs (Figure 6b). The increased coverage in OTCs was too small to confirm the increase. In the third year (1999), the coverage of Lo increased visibly in OTCs (Figure 6a). Because $L o$ grew in creeping, Lo extended canopy, overcoming other species in OTCs. In the same year, Empetrum nigrum $(\mathrm{Em})$ did not increase in coverage and even some of $E m$ died in OTCs (Figure 6), although vegetation growth of $E m$ was larger than that of $L o$ (Tables 2 and 3). In CTRLs, on the contrary, Lo did not increase in coverage at all even in the third year, and also some of $E m$ died (Figure $6 \mathbf{b}$ ). Other forb species such as Vaccinium vitis-idaea (Va), Sieversia pentapetala (Si) and Schizocodon soldanelloides $f$. alpinus (Sc) did not show any changes in coverage both in OTCs and CTRLs. Carex scita also did not change in coverage. On the basis of these results, it may be said that the temperature enhancement made $L o$ more active in increasing in coverage than other species. The possible reasons might be that Loisereuria procumbens captured much nutrient due to the accelerated photosynthesis and easily extended canopy, resulting in disturbing the increase in coverage of other species.

In our research, effects of temperature enhancement were recognized for all ecological aspects observed except for biomass. The effects appeared with variations by species, that is, some species grew more and extended their canopies under temperature enhancement. The results of coverage measurement suggest that under a warming condition, Loisereuria procumbens, which has increased in coverage, might become dominant in terms of exchanging from Empetrum nigrum which is now dominant in our experimental site. However it will take a long time to confirm the whole trend of vegetation change under expected warming in the future. In order to achieve this object, continuous study will be needed presumably for several years. Our experimental research is short term, but it showed some new aspects of vegetation responses to temperature enhancement. They might lead to more new discoveries of ecological dynamics in future studies.

\section{Acknowledgements}

We thank all individuals and organizations who assisted with our research. Especially officers in the Kukuno Kohgen District Forestry Office and the Environmental Agency of Japan gave us permission to perform the experimental research on Mt. Norikura all the time; the staff on Cosmic Ray Observatory, University of Tokyo, kindly supported our staying on the high mountain during the research terms. Also we thank the members of university staff, Prof. Atsumu. Ohmura (ETH, Switzerland), Prof. Kazuo Suzuki, Prof. Kimito Furuta, and Prof. Hisayoshi Yagi who encouraged this research in various ways. Furthermore, Dr. Ikuko Nakashinden (Miyagi University, Japan) instructed us in the method of measurement of plants, and also Dr. Keiji Kimura (Tokyo Metropolitan Univ., Japan) helped us to set up meteorological measurement instruments. In addition, Ms. Setsuko Miyazaki, a secretary of the Department of the Geography, University of Tokyo has been working hard through the years for preparation of our research. This research has been financially supported by Nissan Science Foundation, by the Foundation of the Alliance for Global Sustainability, the University of Tokyo, and by the Research Fund from the Ministry of Education, Science, and Culture of Japan. We also appreciate Dr. G. M. Marion, Desert Research Insti- 
tute, and anonymous reviewers, for their fruitful comments on our paper.

(Received 4 August 2003)

(Accepted 10 December 2003)

\section{References}

Alatato, J. M., and Totland, $\phi .1997$. Response to simulated climate change in an alpine and subarctic Pollen-risk Strategist. Global Change Biology 3 (Suppl. 1): 71-79.

Allaby, M. 1992. A Dictionary of Plant Sciences. Oxford: Oxford University Press.

Anazawa, K., and Ohmori, H. 2000. Chemistry of surface water at a volcanic summit area, Norikura, Central Japan: Multivariate statistical approach. Chemospher 45: 807-816.

Chapin, F. S., and Shaver, G. R., 1985. Individualistic growth response of tundra plant species to environmental manipulations in the field. Ecology 66: 564-576.

Chapin, F. S., Shaver, G. R., Giblin, A. E., Nadeloffer, K. J., and Launder, J. A. 1995. Responses of arctic tundra to experimental and observed changes in climate. Ecology 76: 694-711.

Fukuyo, S., Kurihara, M., Nakashinden, I., Kimura, K. Iijima, Y., Kobayashi, Y., Masuzawa, T., Yamamoto, S., Morimoto, M., Kouyama, T., Kobayashi, S., Yamamoto, T., Mizuno, K., and Machida, H. 1998. Short-term effects of wind shield on phenology and growth of alpine plants in Mt. Kisokomagatake, central Japan. Proceedings of the NIPR Symposium on Polar Biology 11: 147-158.

Gifu Prefecture 1969. The report of academic research of Norikura-dake District. NACS-J (Nihon Shizen Hogo Kyoukai) Chousa Houkoku 36: 2-58.

Haveström M., Callaghan, T. V., and Jonasson, S. 1993. Differential growth responses of Cassiope tetragona, an arctic dwarf-shrub, to environmental perturbations among three contrasting high and subarctic sites. Oikos 66: 389-402.

Henry, G. H. R., and Molau, U., 1997: Tundra plants and climate change: the International Tundra Experiment (ITEX). Global Change Biology 3 (Suppl. 1): $1-9$.

Hodkinson, I. D., Webb, N. R., Bale, J. S., Block, W., Coulson, S. J., and Strathdee, A. T., 1998: Global change and arctic ecosystems: conclusions and predictions from experiments with terrestrial invertebrates on Spitsbergen. Arctic and Alpine Research 30: 306-313.

Iguchi, J. H., Ohmori, H., Ohmura, A., Suzuki, K., Furuta, K., Yagi, H., Ohta, T., Nakashinden, I., Kimura, K., and Sugai, T. 1998. Experimental studies on vegetation changes due to climate warming at the side of Mt. Norikura, central Japan. Bulletin of the Department of Geography, University of Tokyo 30: 17-26.
Kojima, S., Tsubota, M., and Wada, N. 1997. Growth responses of two alpine plants to artificially generated warmed environment in Tateyama range, Toyama, Japan. Proceedings of the NIPR Symposium on Polar Biology 10: 188-195.

Marion, G. M., Henry, G. H. R., Freckman, D. W., Johnstone, J., Jones, G., Jones, M. H., Levesque, E., and Molau, U. 1997. Responses to natural climatic variation and experimental warming in two tundra plant species with contrasting life forms: Cassiope tetragona and Ranunculus nivalis. Global Change Biology 3 (Suppl. 1): 97-107.

Molau, U., and Shaver, G. R., 1997: Controls on seed production and seed germinability in Eriophorum vaginatum. Global Change Biology 3 (Suppl. 1): 80-88.

Molau, U., Molgaard, P., Parsons, A. N., Svoboda, J., and Virginia, R. A. 1997. Open-top designs for manipulating field temperature in high-latitude ecosystems. Global Change Biology 3 (Suppl. 1): 20-32.

Molgard, P., and Christensen, K. 1997. Response to experimental warming in a population of $\mathrm{Pa}$ paver radicatum in Greenland. Global Change Biology 3 (Suppl. 1): 116-124.

Nakano, S., Otsuka, T., Adachi, M., Harayama, S., and Yoshioka, T. 1995. Geology of the Norikuradake District. with geological map at 1 :50,000. Geological Survey of Japan.

Nakashinden, I., Masuzawa, T., Fukuyo, S., Kimura, K., Yamamoto, S., Iijima, Y., Mizuno, K., Kobayashi, S., Yamamoto, T., Machida, H., and Takaoka, S. 1997. A preliminary report on phenological monitoring using experimental chambers in Mt. Kiso-komagatake, central Japan. Proceedings of the NIPR Symposium on Polar Biology 10: 196-204.

Ohmori, H., and Yanagimachi, H. 1998. Temperature changes during the Hypsithermal in Japan estimated from vegetation changes. Bulletin of the Department of Geography, University of Tokyo 30: $1-16$.

Osada, K., Kido, M., Nishita, C., Matsunaga, K., Iwasaka, Y., Nagatani, M., and Nakada, H. 2002. Changes in ionic constituents of free tropospheric aerosol particles obtained at Mt. Norikura (2770 $\mathrm{m}$ a.s.1.), central Japan, during the Shurin period in 2000. Atmospheric Environment 36: 5469-5477.

Robinson, C. H., Wookey, P. A., Parsons, A. N., Potter, J. A., Callaghan, T. V., Lee, J. A., Press, M. C., and Welker, J. M. 1995. Responses of plant litter decomposition and nitrogen mineralisation to simulated environmental change in a high arctic polar semi-desert and a subarctic dwarf shrub heath. Oikos 74: 503-512.

Stenström, M., Gugerli, F., and Henry, G. H. R. 1997. Response of Saxifraga oppositifolia $L$. to simulated climate change at three contrasting latitudes. Global Change Biology 3 (Suppl. 1): 44-54.

Suzuki, D., and Kudo, G. 1997. Short-term effects of 
simulated environmental change on phenology, leaf traits, and shoot growth of alpine plants on a temperature mountain, northern Japan. Global Change Biology 3 (Suppl. 1): 108-115.

Tsukada, M. 1967. Pollen succession, absolute pollen frequency, and recurrence surfaces in central Japan. American Journal of Botany 54: 821-831.

Tsukada, M. 1983. Vegetation and climate during the Last Glacial Maximum in Japan. Quaternary Research 19: 369-381.

Wada, N., Miyamoto, M., and Kojima, S. 1998. Responses of reproductive traits to short-term artificial warming in a deciduous alpine shrub, Geum pentapetalum (Rosaceae). Proceedings of the NIPR Symposium on Polar Biology 11: 137-146.

Wagner, J. and Reichegger, B. 1997. Phenology and seed development of the alpine sedges Carex curvula and Carex firma in responses to contrasting topoclimates. Arctic and Alpine Research 29: 291299.

Welker, J. M., Molau, U., Parsons, A. N., Robinson, C. H., and Wookey, P. A. 1997. Responses of Dryas octopentata to ITEX environmental manipulations: a synthesis with circumpolar comparisons. Global Change Biology 3 (Suppl. 1): 61-73.

Wookey, P. A., Welker, J. M., Parsons, A. N., Press, M. C., Callaghan, T. V., and Lee, J. A. 1994. Differential growth, allocation and photosynthetic responses of Polygonum viviparum to simulated environmental change at a high arctic polar semidesert. Oikos 70: 131-139.

Wright, H. E. Jr., Kutzbach, J. E., Webb, T. III., Ruddiman, W. F., Street-Perrott, F. A., and Bartlein, P. J. eds. 1993. Global Climate since the Last Glacial Maximum. Minneapolis: University of Minnesota Press.

Yanagimachi, O., and Ohmori, H. 1991. Ecological status of Pinus pumila scrub and the lower boundary of the Japanese alpine zone. Arctic and Alpine Research 23: 424-435.

Zhang. Y., and Welker, J. M., 1996, Tibetan alpine tundra responses to simulated changes in climate: aboveground biomass and community responses. Arctic and Alpine Research 28: 203-209. 